\title{
Elucidating the Formation Characteristics of Melamine-Cyanuric Acid Complex
}

F. Akhter, ${ }^{*}$ J. Miller, ${ }^{* *}$ N.S. Chong, ${ }^{*}$ and B.G. Ooi*

* Department of Chemistry, Middle Tennessee State University, Murfreesboro, TN 37132

** MTSU Interdisciplinary Microanalysis and Imaging Center, Middle Tennessee State University, Murfreesboro, TN 37132

Melamine and cyanuric acid have been implicated in the kidney-related disease in infants and in the death of a large number of cats and dogs that ingested tainted food containing melamine. Both incidents were caused by the willful adulteration of the raw ingredients with melamine in the dairy products and pet food, respectively, in order to boost the apparent protein content in the nutritional labels. Melamine and cyanuric acid can form extremely insoluble "needle-like" and "spoke-like" crystals, which are composed of hydrogen-bonded melamine-cyanuric acid complex or melaminecyanurate [1]. Ingested melamine and cyanuric acid are absorbed in the gastrointestinal tract, distributed systemically, and precipitate as the melamine-cyanurate complex in the renal tubules, leading to progressive tubular blockage, degeneration, and acute renal failure [2, 3]. The U. S. Food and Drug Administration (FDA) reported that melamine is incorporated into melamineformaldehyde resins for making food packaging materials, plastic tableware, and the coating of food tins but only residual amounts leach into food. Food and beverage have been found to contain melamine in the parts-per-million levels as a result of leaching from melamine-containing resins [4]. Like melamine, cyanuric acid can be formed as a degradation product of s-triazine pesticides. Trace levels of cyanuric acid can be present in food and water from the use of dichloroisocyanurate in drinking water, swimming pools, and water used in food manufacturing. Cyanuric acid derivatives are found in sanitizing solutions for sanitizing food processing equipment, utensils, and other food contact [5]. According to the FDA, the toxicity of the combination of melamine and cyanuric acid is a "concentration-dependent phenomenon," in which only high doses will lead to the formation of the renal crystals [6].

The goal of this study is to investigate the histomorphologic characteristics of the crystals observed at various concentrations and temperatures using scanning electron microscopy (SEM). The morphology, size, and distribution of the crystals formed at temperature of $4{ }^{\circ} \mathrm{C}, 25^{\circ} \mathrm{C}$, and $37^{\circ} \mathrm{C}$ at initial melamine and cyanuric acid concentrations ranging from $50 \mathrm{ppm}$ to $250 \mathrm{ppm}$ were compared. Preliminary data indicated that the melamine-cyanurate crystals produced at $37^{\circ} \mathrm{C}$ were coarser and larger compared to those formed at $25^{\circ} \mathrm{C}$ (Fig. 1a and b). Furthermore, the proportion of "spoke-like" crystals decreased along with the accompanying increase in the proportion of "needle-like" crystals at the higher temperature of $37^{\circ} \mathrm{C}$. The larger crystal sizes at higher temperature may be due to the slower rate of formation and smaller number of initial nucleation sites. Similarly, lower concentration of $100 \mathrm{ppm}$ complex gave rise to crystal structures that were coarser and larger compared to crystals formed at the same temperature at higher initial concentration of $250 \mathrm{ppm}$ for melamine and cyanuric acid (Fig. 1a and Fig. 2a). Samples containing melamine-cyanurate formed in bovine blood plasma and in the kidney tissue of catfish that had been fed daily for 3 days with 200 milligram per day of melamine-cyanuric acid complex per kilogram of body weight were also analyzed by SEM and Raman microscopy. 
References

[1] L.M.A. Perdigao, N.R. Champness, P.H. Beton, Chem. Commun. 5 (2006) 538.

[2] R.L.M. Dobson, S. Motlagh, M. Quijano, R. T. Cambron, T.R.Baker, A. M. Pullen, B. T. Regg, A. S. Bigalow-Kern, T. Vennard, A. Fix, R. Reimschuessel, G. Overmann, Y. Shan, G.P. Daston, Toxicol. Sci. 106 (2008) 51.

[3] V.L. Yang, D. Batle, The Scientific World Journal 8 (2008) 974.

[4] H. Ishiwata, T. Inoue, T. Yamazaki, K. Yoshihire, J. Assoc. Off Anal. Chem. 70 (3) (1987) 457.

[5] World Health Organization Report (2009). http://www.who.int/foodsafety/publications/chem/Melamine report09.pdf Accessed Feb. 2011

[6] US FDA Report (2008). http://www.fda.gov/Food/FoodSafety/FoodContaminantsAdulteration/ChemicalContaminants/ Melamine/ucm164522.htm. Accessed Feb. 2011
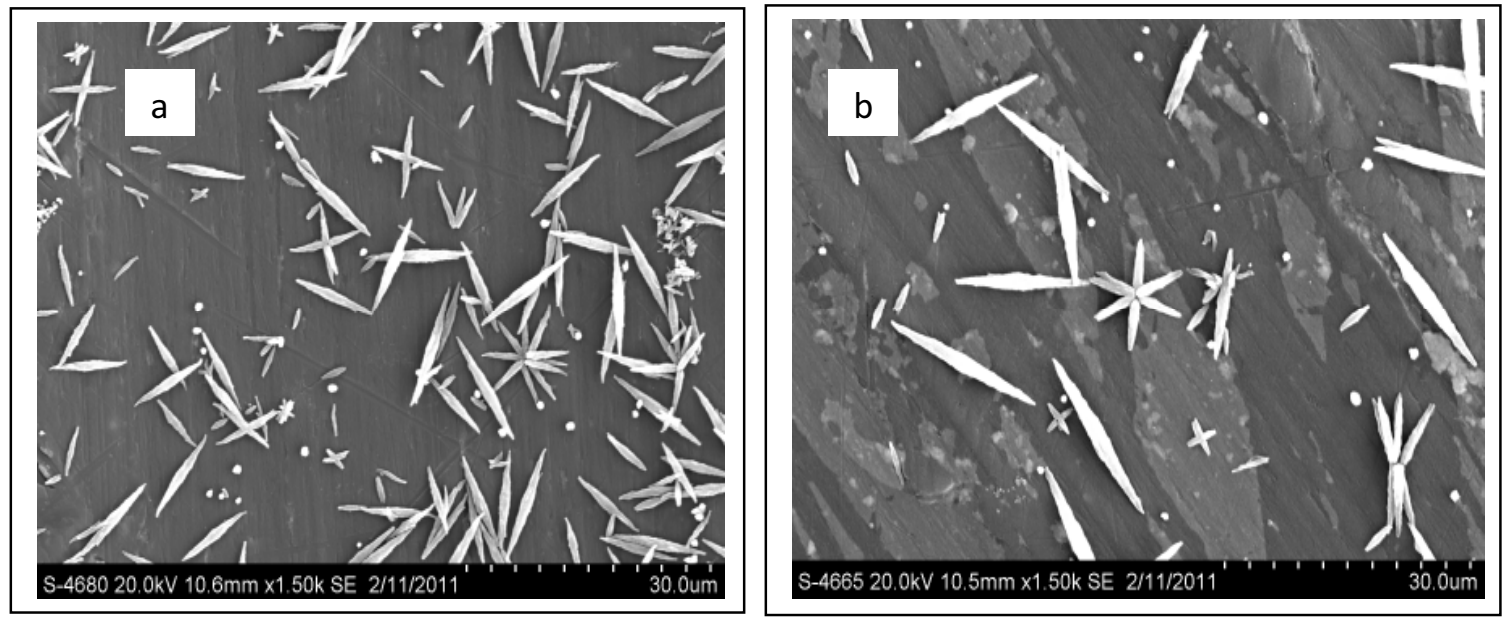

FIG. 1. SEM of melamine-cyanuric acid complex formed from initial $100 \mathrm{ppm}$ solutions.

a) Crystals of complex formed at $25{ }^{\circ} \mathrm{C}$ and b) Crystals of complex formed at $37{ }^{\circ} \mathrm{C}$.


FIG. 2. SEM of melamine-cyanuric acid complex formed from initial $250 \mathrm{ppm}$ solutions.

a) Crystals of complex formed at $25^{\circ} \mathrm{C}$ and b) Crystals of complex formed at $37{ }^{\circ} \mathrm{C}$ 